\title{
TIPOLOGIA DE CONTEÚDOS EM LIVROS DIDÁTICOS DE FÍSICA: Um Estudo em Coleções do PNLD 2015 e 2018
}

\author{
Glêsiane Coelho de Alaor Viana ${ }^{1}$ \\ Maria Inês Martins ${ }^{2}$
}

\begin{abstract}
RESUMO
Os livros didáticos (LDs) representam o principal material didático utilizado nas escolas brasileiras de Educação Básica, sobretudo após a consolidação do Programa Nacional do Livro Didático (PNLD), ao permitir aos professores escolher a coleção de livros mais adequada para cada escola. Este artigo analisa 5 das 14 coleções de Física aprovadas pelo PNLD 2015, 4 delas incluídas no PNLD 2018, usando a tipologia de conteúdos, proposta por Coll e Zabala, a qual classifica os conteúdos em conceitual (C), procedimental (P) e atitudinal (A). A análise documental focalizou as Diretrizes Curriculares Nacionais da Educação Básica (DCNEB) e os Guias de Livros Didáticos (GLD) para o PNLD 2015 e 2018. A análise dos livros contabilizou a distribuição dos tipos de conteúdo, bem como suas combinações CA, CP, PA e CPA. Verificou-se a ênfase no conteúdo conceitual (C) em todas as coleções, destacando-se sua associação com conteúdo procedimental (CP), em virtude do elevado número de exercícios presentes nos LDs de Física. Observou-se, também, pouca ênfase ao conteúdo atitudinal. Duas coleções apresentaram propostas mais próximas ao conceito de formação humana integral, proposto pelas DCNEB. Espera-se que esta pesquisa auxilie professores de Física na incorporação da tipologia de conteúdos em suas aulas e programas de ensino.
\end{abstract}

Palavras-chave: Livro didático de Física. Tipologia de conteúdos. PNLD 2015. PNLD 2018.

TYPOLOGY OF CONTENTS IN PHYSICS TEXTBOOKS: A STUDY IN PNLD 2015 AND 2018 COLLECTIONS

\begin{abstract}
Textbooks (LD) represent the main didactic material used by Brazilian Elementary and High Schools, especially after the consolidation of the National Textbook Program (PNLD), which allows teachers to choose the most suitable book series for each school. This paper analyzes five of the fourteen Physics book series approved in the PNLD 2015, four of them are also included in PNLD 2018. The textbooks analysis were based on the typology of contents, proposed by Coll and Zabala, which classify the contents as conceptual $(C)$, procedural $(P)$, and attitudinal $(A)$. The document analysis focused on the National Curricular Guidelines for schools (DCNEB) and pedagogical descriptions for PNLD 2015 and PNLD 2018 textbook guides (GLD). The books analyses involved counting the distribution of contents, and their associations CA, CP, PA and CPA. In all book series, we found that the emphasis was conceptual content, and also its association with procedural (CP) content, due to a large number of exercises presented in Physics textbooks. There was little emphasis on attitudinal content as well. Two book series presented perspectives closer to the holist education concept proposed by the DCNEB. We hope this research will assist Physics teachers to incorporate typology of contents in class preparation and course planning.
\end{abstract}

Keywords: Physics textbook. Typology of contents. PNLD 2015. PNLD 2018.

Recebido em: 27/3/2019

Aceito em: 27/5/2019

\footnotetext{
Mestre em Ensino de Ciências e Matemática (área de concentração Ensino de Física) pela Pontifícia Universidade Católica de Minas Gerais (PUC/Minas). Licenciada em Física pela PUC/Minas e com Especialização em Ensino de Física e Ensino de Matemática pela Faculdade de Administração, Ciências, Educação e Letras. Professora de Educação Superior na Universidade Estadual de Minas Gerais (Unidade Ibirité/ MG) e professora de Educação Básica da Escola Estadual Antônio Marinho Campos, também no município de Ibirité/MG. http://lattes. cnpq.br/7235122011084299. https://orcid.org/0000-0002-3096-2468. glesiane.viana@uemg.br

2 Graduação em Física pela Universidade de São Paulo (1979). Mestrado em Física pela Universidade Federal de Minas Gerais (1989) e Doutorado em Educação pela Universidade Estadual de Campinas (2002). Professora-adjunta da Pontifícia Universidade Católica de Minas Gerais e servidora ad hoc do Instituto Nacional de Estudos e Pesquisas Educacionais. É líder do grupo de pesquisa (CNPq) Livros Didáticos de Ciências e Matemática. Tem experiência na área de educação, com ênfase em Planejamento e Avaliação Educacional, bem como na área de Ensino de Física, atuando principalmente nos seguintes temas: livros didáticos e exames de larga escala. http://lattes.cnpq. br/4924903522361187.https://orcid.org/0000-0002-6412-9749. ines@pucminas.br
} 
Ao analisar a história educacional brasileira verifica-se a influência curricular do livro didático (LD) desde as primeiras tentativas de organização do sistema escolar do país. De fato, do ponto de vista histórico, Ferreira e Selles (2004) consideram o LD como um poderoso mecanismo de seleção e de organização dos conteúdos e métodos de ensino, além de importante componente nos processos de reconstrução curricular, apesar de assumir variados formatos e, consequentemente, múltiplas finalidades e usos nos diversos contextos escolares. O destaque do LD entre os demais recursos pedagógicos ocorre em razão das suas várias possibilidades de uso, configurando-se, na visão de Pavão (2006), em suporte de conhecimentos e de métodos para o ensino, servindo como orientação para as atividades de produção e reprodução de conhecimento e, em muitas ocasiões, como única referência ao trabalho do professor, assumindo o papel de currículo e definindo estratégias de ensino.

Para Prado e Martins (2014), a escolha adequada do LD, como material único e acessível, permite ao professor o acesso a uma ampla variedade de informações, procedimentos e atividades, inclusive atividades práticas, sem a necessidade de avançados laboratórios de Ciências, disponíveis em poucas escolas. Segundo Pavão (2006), cabe ao professor utilizar o LD de forma apropriada e contextualizada no processo ensino-aprendizagem, com base em um bom projeto educacional, pautado na postura de um professor atuante, com uma prática que se apropria da realidade como instrumento pedagógico. A importância da ação do professor é também reforçada por Calais (2014) ao delinear o papel do texto escolar como ferramenta educacional na atividade pedagógica e a sua adequação ao contexto da escola em que atua.

Choppin (2004) enumerou as múltiplas funções de um LD. Na função referencial, o LD serve como suporte para os conteúdos educativos. Na função instrumental, permite colocar em prática os métodos de aprendizagem. Na função ideológica e cultural, o LD configura-se como portador essencial da língua, da cultura e dos valores das classes dirigentes. Por fim, na função documental, mais recente na literatura escolar, o LD permite o desenvolvimento crítico do aluno, em busca de sua autonomia.

Selles e Ferreira (2004), buscando compreender diversas funções do LD, propuseram três dimensões pedagógicas. A primeira dimensão, relacionada ao currículo, refere-se ao confronto histórico que envolve intenções e interesses dos diversos grupos ligados às ciências de referência (Biologia, Física e Química), bem como dos variados grupos acadêmicos e autoridades educacionais, em que esses materiais seriam um testemunho visível e público dos diversos embates que são travados em torno das decisões que envolvem a seleção e a organização do conhecimento escolar. A segunda dimensão, a ação didática, refere-se ao reconhecimento docente do LD, visto não somente como seleção dos conteúdos a serem ensinados, mas também como um conjunto de propostas pedagógicas que passa a influenciar de modo decisivo a ação docente. Por fim, a terceira dimensão, ligada à formação de professores, coloca o LD como possível substituto de uma preparação profissional inicial e continuada mais sólida. Nesse sentido, as autoras relacionam a preparação inadequada de professores à utilização do livro didático.

Diante da sua relevância como suporte de conhecimento, fonte de métodos e de referências para o trabalho docente, destacam-se vários estudos sobre o LD. Martins e Garcia (2014) enumeram as principais linhas de investigação sobre publicações didáti- 
cas, com diferentes enfoques e abordagens, surgidas a partir da década de 80 do século 20. A principal linha é a análise do conteúdo dos livros do ponto de vista crítico, histórico ou ideológico. Zambon e Terrazan (2012) também constatam que os estudos têm se dedicado, em sua maioria, à análise de conteúdo ou à utilização de recursos e estratégias didáticas. A adoção de novos referenciais teórico-metodológicos permite a extensão substancial das formas de investigar os LDs, permitindo que sejam entendidos em seu contexto de produção e de utilização.

Para Coll (1998), os conteúdos escolares constituem-se em seleção de formas ou saberes culturais, cuja assimilação é considerada essencial para que se produza um desenvolvimento e uma socialização adequada dos estudantes dentro da sociedade à qual pertencem. Além disso, para que se configurem como conteúdos de ensino e aprendizagem nas propostas curriculares, esses saberes e formas culturais devem requerer adequação e planificação específica para sua assimilação correta e plena. Zabala (1998) propõe uma tipologia para identificar com maior precisão as intenções educativas. Para o autor, os conteúdos podem ser tipificados em Conteúdos Factuais e Conceituais, Conteúdos Procedimentais e Conteúdos Atitudinais, sendo os primeiros relativos a fatos e conceitos mais enfatizados nas práticas educativas, em detrimento aos procedimentos, as atitudes, valores e normas, que também devem ser objeto de ensino e aprendizagem na escola.

Nesse sentido, Prado e Martins (2014), Calais (2016) e Calais e Martins (2018) usam a tipologia de conteúdos, proposta por Coll (1987) e aplicada por Zabala (1998), para analisar a Física presente em coleções de Ciências Naturais do Ensino Fundamental recomendadas em edições do PNLD. Os autores observam a priorização dos conteúdos conceituais nos LDs analisados e destacam os conteúdos conceituais procedimentais, em detrimento dos conteúdos atitudinais e atitudinais procedimentais. Na presente pesquisa, os mesmos pressupostos são aplicados em LD de Física, aprovados pelos PNLD 2015 e 2018, no intuito de observar, nas obras selecionadas, a distribuição da tipologia de conteúdos. A partir dos dados oficiais estatísticos consolidados do PNLD 2015 (ciclo de referência: 2015 a 2017) foram selecionadas quatro coleções de Física, respectivamente, mais e menos distribuídas, além da obra mais referenciada por docentes pesquisados. ${ }^{3}$ Quatro entre as cinco coleções analisadas também integram o PNLD 2018.

Foram analisadas as resenhas fornecidas nos Guia de Livros Didáticos PNLD 2015 e 2018 (BRASIL, 2014, 2017) e as edições do professor dos LDs selecionados, em que se encontram informações sobre a organização da coleção e as suas referências. A análise dos LDs contemplou o texto e as propostas de atividades, na indicação dos conteúdos conceituais, procedimentais e atitudinais. Foram também apreciadas as Diretrizes Curriculares Nacionais da Educação Básica, publicadas em 2013, com enfoque nas suas referências ao Ensino Médio, bem como no conceito de formação humana integral, ora consubstanciada na abordagem dos três tipos de conteúdo propostos por Coll (1987)

\footnotetext{
3 Por meio de um questionário foi realizado o levantamento de dados a respeito do perfil de professores que utilizam o LD. Participaram da pesquisa professores de Física de escolas estaduais diversas da região metropolitana de Belo Horizonte, em especial do município de Ibirité, em que todos os docentes que atuam no Ensino Médio responderam ao instrumento de coleta de dados.
} 
e tratados por Zabala (1998). Dessa forma, a identificação e classificação dos conteúdos possibilitaram compreender se as coleções estão alinhadas ao proposto nas DCNEB para o Ensino Médio, no que diz respeito a

... proporcionar ao estudante uma formação com base unitária, no sentido de um método de pensar e compreender as determinações da vida social e produtiva; que articule trabalho, ciência, tecnologia e cultura na perspectiva da emancipação humana (BRASIL, 2013, p. 39).

\section{TIPOLOGIA DE CONTEÚDOS}

Para tipificar os conteúdos foram adotadas as propostas complementares de Coll (1987) e Zabala (1998). Coll (1987, p. 161) entende por conteúdos

... o conjunto de formas culturais e de saberes selecionados para integrar as diferentes áreas curriculares em função dos Objetivos Gerais de Área. ${ }^{4}$ Os conteúdos podem ser fatos discretos, conceitos, princípios, procedimentos, valores, normas e atitudes.

Para o autor, o conjunto de objetos, acontecimentos ou símbolos com algumas características comuns é definido como um conceito, como a força. Os enunciados que descrevem as relações entre as mudanças que ocorrem com conceitos diferentes (relações de causa e efeito, covariação) são denominados princípios, a exemplo da Lei da Gravidade. Como procedimento, tem-se "o conjunto de ações ordenadas e finalizadas, isto é, orientadas para a consecução de uma meta", o que pode ser exemplificado pela resolução de um exercício. Também são utilizados termos como destreza, técnica, método ou estratégia para se referir a esse tipo de conteúdo. Um valor seria um "princípio normativo que preside e regula o comportamento das pessoas em qualquer momento e situação", como o respeito à vida e à natureza. A concretização dos valores ocorre na forma de normas, regras de comportamento que devem ser respeitadas pelas pessoas em determinadas situações. Por fim, atitude configura-se como uma tendência de comportamento consistente e persistente perante determinada situação, objeto, acontecimento ou pessoa, refletindo um maior ou menor respeito a determinados valores e normas, como comportamento de ajudar, de respeitar, entre outros. Com base nessas definições, o autor classifica os conteúdos do ensino obrigatório em três grandes categorias:

[...] fatos, conceitos e princípios (os princípios descrevem relações entre conceitos e estes se referem sempre, em última instância, a fatos discretos); procedimentos; valores, normas e atitudes (estes três tipos de conteúdos formam um contínuo, pois as atitudes são a correlação comportamental entre valores e normas) (COLL, 1987 , p. 163, grifos do autor).

Segundo Zabala (1998), são conteúdos de aprendizagem todos aqueles que possibilitem o desenvolvimento das capacidades motoras, afetivas, de relação interpessoal e de inserção social, cuja natureza é muito variada (dados, habilidades, técnicas,

${ }^{4}$ De acordo com Coll (1987, p. 159), os Objetivos Gerais de Área "indicam as capacidades que o aluno deve ter adquirido em cada área curricular ao final do ciclo correspondente". 
atitudes, conceitos, entre outros). Assim, um conteúdo de aprendizagem é tudo que se deve aprender para alcançar determinados objetivos, abarcando assim todos os tipos de capacidades cognitivas. Segundo o autor (p. 30-31), a classificação feita por Coll (1987) é adequada aos conteúdos de aprendizagem por sua potencialidade explicativa de fenômenos educativos, destacando-se que a classificação em conteúdos conceituais, procedimentais ou atitudinais responde, respectivamente, às perguntas "o que se deve saber?", "o que se deve saber fazer? " e "como se deve ser? ", com o fim de alcançar as capacidades propostas nas finalidades educacionais.

Zabala (1998) esclarece ainda que os conteúdos factuais englobam o conhecimento dos fatos, acontecimentos, situações, dados e fenômenos concretos e singulares, indispensáveis para a compreensão da maioria das informações e problemas da vida cotidiana e profissional. Os princípios referem-se às mudanças que se produzem num fato, objeto ou situação em relação a outros fatos, objetos ou situações e que normalmente descrevem relações de causa-efeito ou de correlação. Apesar de serem termos abstratos, os dois tipos de conteúdo (conceitos e princípios) podem ser tratados de forma conjunta do ponto de vista educacional, pois ambos necessitam de compreensão, para além da reprodução de enunciados literais.

Os conteúdos procedimentais são, para o autor, formados pelo conjunto de ações ordenadas e dirigidas para a realização de objetivo, que incluem as regras, as técnicas, os métodos, as destrezas ou habilidades, as estratégias, os procedimentos. Esses conteúdos exibem características específicas quanto a sua aprendizagem, pois esta pode ter aspectos motores ou cognitivos, envolver poucas ou muitas ações e ter diferentes graus de determinação da ordem das sequências. Por fim, caracterizam-se como conteúdos atitudinais agrupados em valores, atitudes e normas. Valores, atitudes e normas estão relacionados e configuram-se por componentes cognitivos (conhecimentos e crenças), afetivos (sentimentos e preferências) e condutas (ações e declarações de intenção).

Zabala (1998) utiliza a diferenciação dos conteúdos para realizar uma caracterização distintiva entre as etapas do sistema educacional. Como a importância dos conteúdos é relativa e característica de cada etapa, o autor considera a existência de um equilíbrio maior na distribuição dos diferentes conteúdos ao longo da formação básica do estudante, sugerindo que, em geral, ocorre a priorização de conteúdos procedimentais e atitudinais em relação aos conceituais nas primeiras etapas do ensino. Coll (1987) menciona essa tendência para os primeiros ciclos do ensino obrigatório, quando ainda há prevalência dos conteúdos do tipo "fatos, conceitos e princípios". Com o avanço no nível de escolarização, espera-se enfatizar mais os conteúdos conceituais, em detrimento aos procedimentais e atitudinais. No Ensino Médio espera-se, portanto, que sejam preconizados em maior parte os conteúdos conceituais. No presente trabalho verifica-se essa tendência de livros didáticos.

Conforme explicitado nas DCNEB, pressupõe-se que o processo de ensino/aprendizagem propicie ao aluno uma formação integral e entende-se que a abordagem e o desenvolvimento da tipologia de conteúdos auxiliem o alcance de tal meta. Nessa perspectiva, espera-se observar nos LDs os diferentes tipos de conteúdo, com as ressalvas e características anteriormente mencionadas para as várias etapas da Educação Básica. De fato, no ensino de determinado conteúdo factual, conceitual, procedimental ou 
atitudinal, deve-se considerar que "todo conteúdo, por mais específico que seja, será associado e, portanto, aprendido junto com os conteúdos de outra natureza" (ZABALA, 1998, p. 40).

Se os diferentes tipos de conteúdo devem estar presentes na proposta de ensino e em todo material que permeia a prática docente, torna-se necessário que o docente saiba identificá-los, bem como verificar as suas possíveis associações. Sendo assim, considera-se que a análise dos LDs, por meio da tipologia dos conteúdos, permite ao docente organizar melhor o seu planejamento de acordo com sua intenção educativa, buscando observar as variadas formas de aprendizagens oriundas dos diferentes conteúdos de ensino.

\section{METODOLOGIA}

Na presente investigação qualitativa de caráter descritivo, os resultados foram obtidos a partir da análise de diferentes fontes de dados, o que, segundo Bogdan e Biklen (1994), incluem uma variedade de documentos. Foram usados os LDs, as DCNEB, os Guias do PNLD, dados estatísticos do FNDE, entre outros. A análise dos LDs pautou-se na tipologia de conteúdos adotada por Zabala (1998). A análise documental, na concepção de Bardin (2016), buscou informações em documentos, com o objetivo de condensá-las para armazenagem e consulta posterior de forma facilitada.

A vigência do PNLD 2018 encerra-se em 2021, o que torna, por ora, indisponível os dados consolidados dessa edição do Programa. A edição do PNLD 2015 apresenta dados estatísticos disponibilizados no site do FNDE. Para o componente curricular Física foram distribuídos mais de 7,5 milhões de exemplares, entre livros do aluno e manuais do professor. ${ }^{5} \mathrm{O}$ Quadro 1 apresenta a relação das coleções analisadas, bem como o código utilizado na análise e o número de exemplares distribuídos por coleção. Quanta Física é a única coleção relacionada na presente análise que não figura no Guia Digital do PNLD 2018. A coleção Física Contexto \& Aplicações, de Luz e Álvares (2013), que segundo Silva (2017, p. 120) "é um best-seller entre os materiais didáticos nacionais", como coleção mais citada pelos professores pesquisados, ${ }^{6}$ foi a quarta mais distribuída no PNLD 2015. ${ }^{7}$ A seguir apresentam-se as coleções objeto de análise, em ordem crescente do número de exemplares distribuídos, respectivamente identificadas por FB, SP, FCA, CFA e QF:

\footnotetext{
Fonte: https://www.fnde.gov.br/programas/programas-do-livro/livro-didatico/dados-estatisticos

Dos professores que responderam ao questionário da pesquisa, 54,5\% indicaram como livro de trabalho a coleção de Luz e Álvares (2013). Apesar de ser a quarta coleção em número de exemplares distribuídos, sua influência, ainda que regional, pôde ser verificada na resposta de um dos docentes mais experientes quando perguntando sobre a motivação da escolha. De acordo com o referido professor, não houve dúvida em optar por esse título, por se tratar de "um clássico da Física".

Fonte: https://www.fnde.gov.br/programas/programas-do-livro/livro-didatico/dados-estatisticos
} 
Quadro 1 - Relação das Coleções Analisadas

\begin{tabular}{|c|l|l|c|c|}
\hline Colocação & \multicolumn{1}{|c|}{ Título } & \multicolumn{1}{|c|}{ Autores } & $\begin{array}{c}\text { Código para } \\
\text { análise }\end{array}$ & $\begin{array}{c}\text { Número de } \\
\text { exemplares } \\
\text { distribuídos }\end{array}$ \\
\hline $1 ㅇ$ & Física & Bonjorno, J. R. et al. & FB & 1.408 .996 \\
\hline $2 ㅇ$ & Ser Protagonista & Stefanovits, A. & SP & 890.843 \\
\hline $4 ㅇ$ & Física Contexto \& Aplicações & Luz, A. M.; Álvares, B. A. & FCA & 581.634 \\
\hline $13 ㅇ$ & Compreendendo a Física & Gaspar, A. & CFA & 216.288 \\
\hline $14 ㅇ$ & Quanta Física & Menezes, L. C. et al. & QF & 98.222 \\
\hline
\end{tabular}

Fonte: Adaptado de BRASIL (2014).

Para quantificar os conteúdos presentes nas coleções analisadas cada página foi tratada individualmente para identificação da presença de conteúdos conceituais, procedimentais e atitudinais. As subdivisões de cada tipo de conteúdo são apresentadas no Quadro 2:

Quadro 2 - Tipos de Conteúdo e suas Subdivisões

\begin{tabular}{|l|l|}
\hline Conteúdos & \multicolumn{1}{|c|}{ Subdivisões } \\
\hline \multirow{5}{*}{ Conceituais } & 1) Fatos \\
\hline & 2) Conceitos \\
\hline & 3) Princípios \\
\hline \multirow{5}{*}{ Procedimentais } & 1) Observação \\
\hline & 2) Experimentação \\
\hline & 3) Comparação \\
\hline & 4) Elaboração de hipóteses e suposições \\
\hline & 5) Debate oral sobre hipóteses \\
\hline & 6) Estabelecimento de relações entre fatos, fenômenos e ideias \\
\hline & 9) Busca de informações em fontes variadas \\
\hline & 10) Elaboração de questões para enquete \\
\hline & $\begin{array}{l}\text { 11) Organização de informações por meio de desenhos, tabelas, gráficos, esquemas e } \\
\text { textos }\end{array}$ \\
\hline & 12) Confronto de suposições e entre elas e os dados obtidos por investigação \\
\hline & 13) Elaboração de perguntas e problemas \\
\hline & 14) Proposição para a solução de problemas \\
\hline \multirow{5}{*}{ Atitudinais } & 1) Valores \\
\hline & 2) Normas \\
\hline & 3) Atitudes \\
\hline
\end{tabular}

Fonte: Elaborado pelas autoras.

A organização dos dados foi consolidada e o resultado totalizado das coleções é apresentado em seguida.

\section{Análise das Coleções}

Foram contabilizadas nas coleções analisadas 4.231 páginas. O Gráfico 1 mostra o consolidado da distribuição dos conteúdos. 
Gráfico 1 - Consolidado da Tipologia de Conteúdos de Física nas Coleções Analisadas

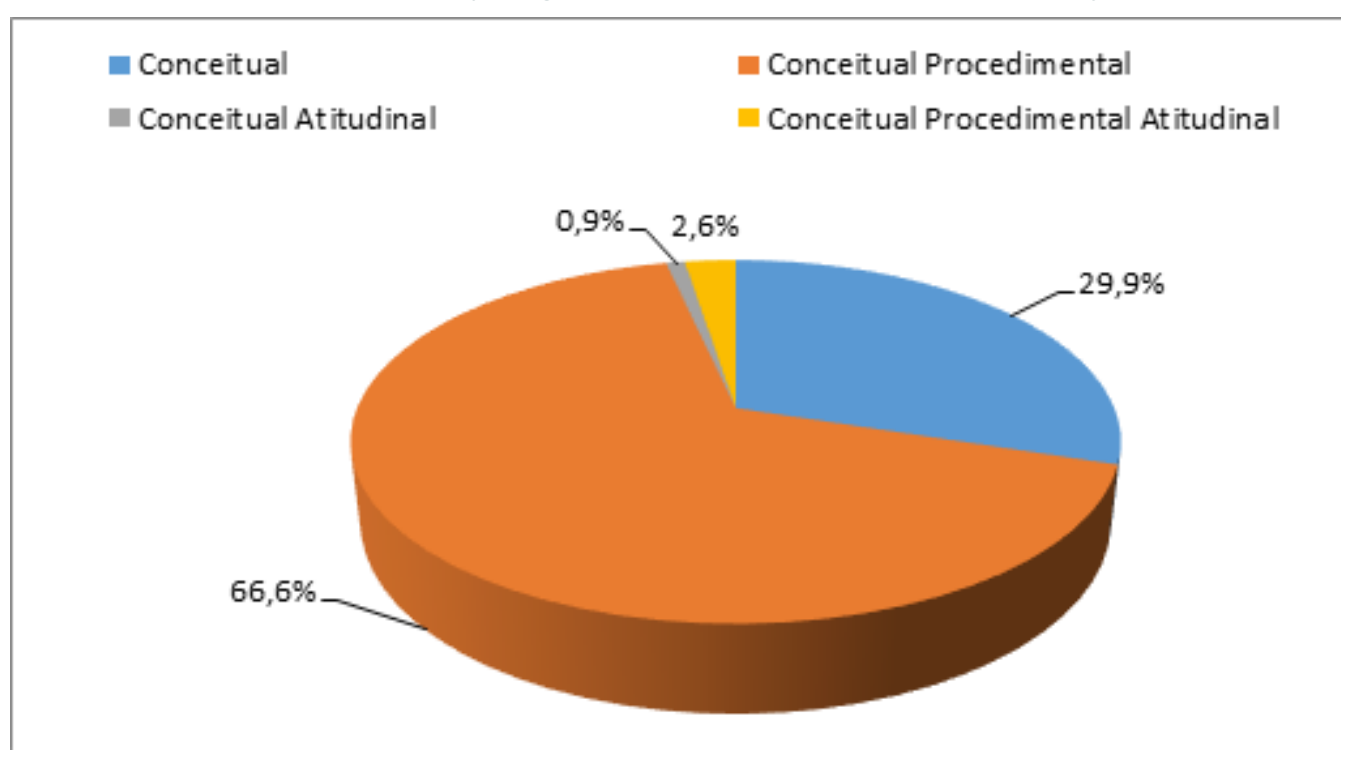

Fonte: Dados da pesquisa.

Os resultados mostram a predominância dos conteúdos conceituais (C), os quais aparecem sozinhos ou associados aos procedimentais e atitudinais. Confirma-se, assim, o que Coll (1987) e Zabala (1998) afirmam a respeito da ênfase no conteúdo conceitual à medida que se avança no nível de escolarização. Quando analisados por categorias, os conteúdos do tipo conceitual procedimental (CP) são os que apresentam maior porcentagem. Em contrapartida, é reduzida a quantidade de conteúdo atitudinal, sempre identificado em conjunto com o conceitual (CA) ou também com o procedimental (CPA). Apresenta-se, a seguir, a distribuição de tipologia de conteúdos por coleção analisada (Gráfico 2).

Gráfico 2 - Tipologia de Conteúdos de Física por Coleção

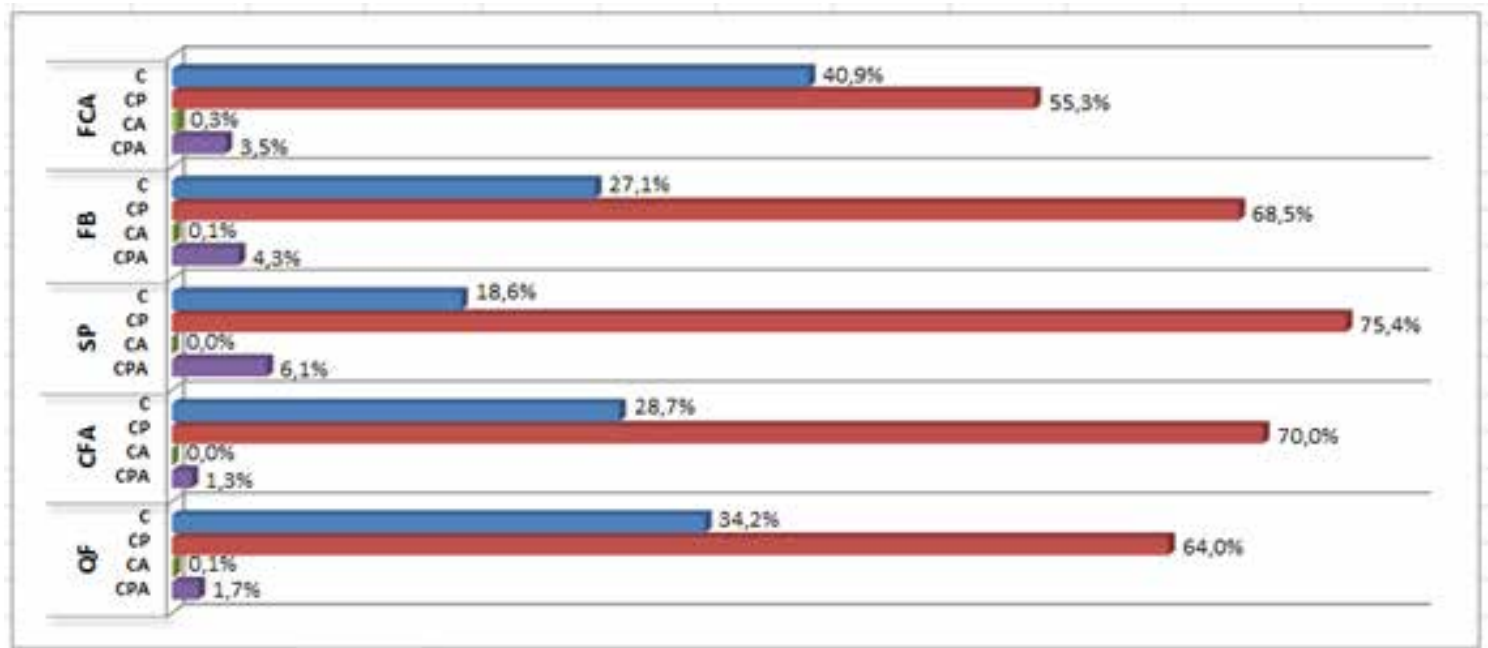

Fonte: Dados da pesquisa. 
Em todas as coleções destaca-se a predominância de conteúdo conceitual procedimental (CP), principalmente em função do grande número de atividades, exercícios (resolvidos ou propostos) e problemas que fazem parte dos LDs de Física. Em média, cada coleção apresentou cerca de 464 páginas com esse tipo de conteúdo. O conteúdo conceitual atitudinal (CA) foi o menos recorrente em todas as obras, presente em pouquíssimas páginas. Percebe-se que a coleção SP mostra abordagem tipológica mais distante das demais, com porcentagem maior de páginas com conteúdo tipo $\mathrm{CP}$ e menor índice de conteúdo tipo $C$, enquanto na coleção FCA encontra-se a menor diferença na distribuição referente a esses dois tipos de conteúdo. Adiante será exemplificada na coleção FCA.

O Gráfico 3 consolida o resultado geral da distribuição das coleções nos três tipos de conteúdo conceituais: Fatos (Tipo 1), Conceitos (Tipo 2) e Princípios (Tipo 3). Classificaram-se como fatos as fotografias devidamente referenciadas e legendadas que se referem a acontecimentos ou fenômenos concretos e às citações de fatos, personagens e descobertas históricas. Foram considerados conceitos as definições apresentadas a respeito de objetos, acontecimentos ou símbolos com características comuns e como princípios as leis matemáticas ou conceituais, com enunciados que descrevem as mudanças de conceitos diferentes.

Gráfico 3 - Consolidado da Classificação dos Conteúdos Conceituais nas Coleções Analisadas

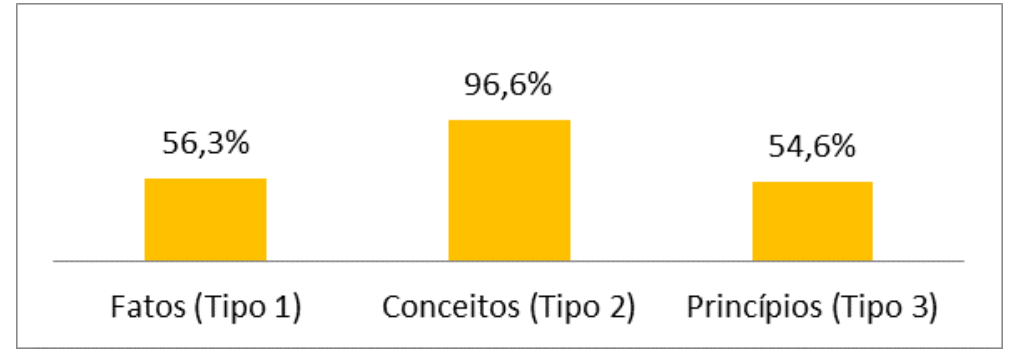

Fonte: Dados da pesquisa.

No Gráfico 3 verifica-se que o Tipo 2 (Conceitos) é o predominante nas coleções analisadas, pois está presente em diversas seções de cada obra. Os fatos e princípios apresentam índices semelhantes quando a análise é consolidada. A coleção QF propõe a construção de uma rede de conhecimento em espiral, com os conceitos organizados a partir de contextos, enquanto que as demais coleções adotam uma sequência de conteúdos que pode ser considerada mais tradicional. Todas as coleções incorporam em suas propostas a interdisciplinaridade e a contextualização do conteúdo, conforme exige 0 artigo $5^{\circ}$, do item $\mathrm{VI}$, das DCNEM (BRASIL, 2013). Nas coleções CFA e FCA, no entanto, a interdisciplinaridade e a contextualização não são elementos principais de organização didático-pedagógica. Na coleção FB observa-se que a contextualização é mais marcante do que a interdisciplinaridade.

Para caracterizar os conteúdos procedimentais foi utilizada a categorização proposta por Prado e Martins (2014), na qual esses conteúdos podem ser encaixados em 14 diferentes tipos, ora apresentados: 1) Observação, 2) Experimentação, 3) Comparação, 4) Elaboração de hipóteses e suposições, 5) Debate oral sobre hipóteses, 6) Estabelecimento de relações entre fatos, fenômenos e ideias, 7) Leitura e escrita de textos infor- 
mativos, 8) Elaboração de roteiros de pesquisa bibliográfica, 9) Busca de informações, 10) Elaboração de questões para enquete, 11) Organização de informações por meio de desenhos, tabelas, esquemas e textos, 12) Confronto de suposições e os dados obtidos por investigação, 13) Elaboração de perguntas e problemas, 14) Proposição para a solução de problemas. 0 resultado consolidado dessa distribuição encontra-se no Gráfico 4.

Gráfico 4 - Consolidado da Classificação dos Conteúdos Procedimentais nas Coleções Analisadas

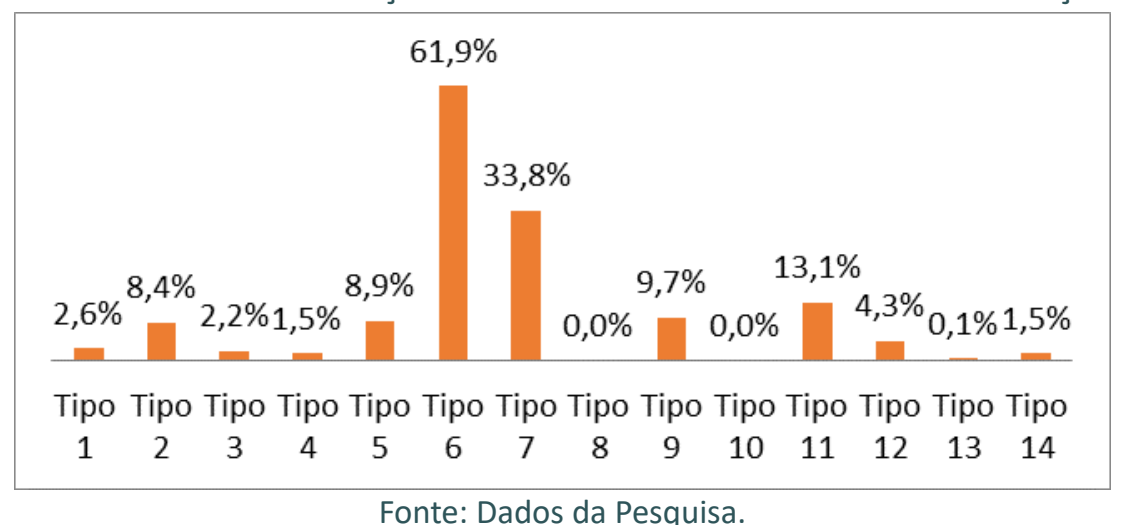

Fonte: Dados da Pesquisa.

Nas páginas contendo $\mathrm{CP}$, o Tipo 6 (Estabelecimento de relações entre fatos, fenômenos e ideias) foi encontrado em $61,9 \%$ delas, constituindo o tipo mais recorrente. Também se destaca o CP Tipo 7 (Leitura e escrita de textos informativos), pois todas as obras oferecem textos complementares para a leitura, com ou sem questões para serem resolvidas. Percebe-se ainda que vários textos apresentados podem ser usados para discussões mais amplas, requerendo, inclusive, outros tipos de conteúdo procedimental, além de conteúdos atitudinais. Não foram identificados em nenhuma coleção os Tipos 8 (Elaboração de roteiros de pesquisa bibliográfica) e 10 (Elaboração de questões para enquete). A maior parte dos exercícios, atividades e problemas, resolvidos ou propostos, foram caracterizados como Tipo 6 (Estabelecimento de relações entre fatos, fenômenos e ideias), pois se referem a questões envolvendo a aplicação de algum princípio ou interpretação de fenômenos. Das obras analisadas, a coleção QF foi a única que não apresentou exercícios resolvidos ao longo dos capítulos. Nas demais obras, em alguns casos, as atividades propostas estavam inseridas em novos contextos e parte consistia em repetições dos exemplos/exercícios resolvidos apresentados ao longo das seções.

Em concordância com Calais (2014 ) e Calais e Martins (2018), foi possível identificar numa mesma atividade diferentes tipos de conteúdo CP. As atividades experimentais identificadas nas coleções, além de trazerem o Tipo 2 (Experimentação), frequentemente continham o Tipo 11 (Organização de informações...) e o Tipo 12 (Confronto de suposições...). Também foi encontrada nas atividades experimentais a maior parte do CP Tipo 1 (Observação).

Os conteúdos atitudinais foram classificados em Valores (Tipo 1), Normas (Tipo 2) e Atitudes (Tipo 3) e, conforme esperado, ocorreram pouco nas coleções analisadas. Prado e Martins (2014) constataram a mesma tendência para os LDs de Ciências recomendados pelo PNLD 2011 e 2008 e Calais (2014 ) a detectou na análise realizada nas coleções de Ciências do PNLD 2014. O Gráfico 5 mostra o consolidado nas coleções analisadas. 
Gráfico 5 - Consolidado da Classificação dos Conteúdos Atitudinais nas Coleções Analisadas

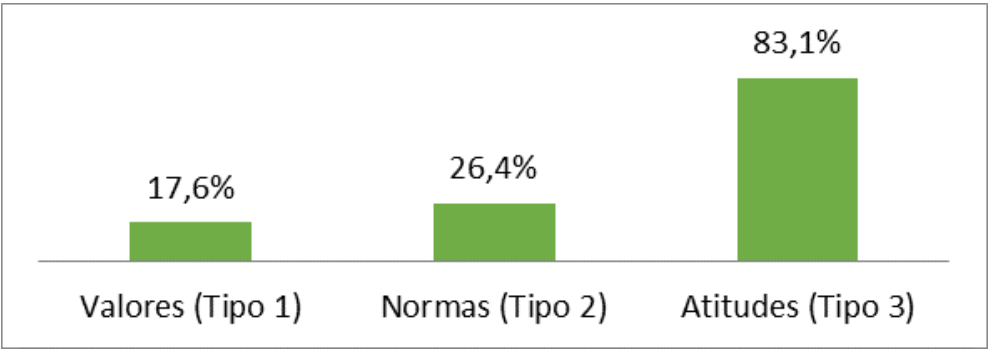

Fonte: Dados da pesquisa.

Observa-se no Gráfico 5 que 83,1\% do conteúdo atitudinal é do Tipo 3 (Atitudes). Segundo Coll (1998, p. 124), valores, atitudes e normas "atuam de modo inter-relacionado e assim devem ser tratados em qualquer enfoque que procure abordar a realidade e explicar o que ocorre". Dessa forma, foi comum a identificação de mais de um tipo de conteúdo atitudinal numa mesma página ou atividade. As atitudes foram identificadas em situações que sugeriam condutas relacionadas a determinadas situações, objetos, acontecimentos ou pessoas e por diversas vezes estavam acompanhadas de valores. As normas, em grande parte, consistem em citações de diferentes tipos de regras e legislação de forma geral.

A seguir exemplifica-se a análise feita, por intermédio da coleção FCA, a 4ạ em distribuição nacional, considerada referência para o ensino de Física e a mais citada pelos professores pesquisados.

\section{Coleção FCA: Física Contexto \& Aplicações, de Luz e Álvares}

A coleção FCA (LUZ; ÁLVARES, 2013) está organizada em unidades, divididas em capítulos. Os conceitos e deduções matemáticas são apresentados ao longo do texto principal. Há seções em forma de boxes: Aplicações da Física, com aplicações tecnológicas; Física no Contexto, com leituras complementares; Integrando..., com relações com outras áreas do conhecimento, e Infográfico, com temas diversos, no final de cada unidade. Os exercícios, problemas e testes estão divididos em: Verifique o que aprendeu e Problemas e testes, com diferentes níveis de dificuldade. Por fim, a seção Pratique Física traz observações e atividades experimentais simples.

O conteúdo conceitual (C) foi identificado em todas as páginas da coleção, de forma isolada, ou em conjunto com o conteúdo procedimental e/ou atitudinal. Na abertura de cada unidade há uma imagem sobre o tema a ser abordado, um pequeno texto para contextualização e a enumeração dos capítulos, classificados como conteúdo conceitual (C). O conteúdo ao longo do texto principal também recebeu essa classificação (Figura 1). 
Figura 1 - Exemplo de Conteúdo Conceitual Tipo 1 (Fatos), Tipo 2 (Conceitos) e Tipo 3 (Princípios)

\begin{tabular}{|c|c|}
\hline \multicolumn{2}{|c|}{$\begin{array}{l}\text { Conteúdo Conceitual Tipo } 2 \text { (Conceitos) } \\
\text { A LEI DE STEFAN-BoltzMANN }\end{array}$} \\
\hline $\begin{array}{l}\text { Consideremos um objeto cuja superficie externa tenha uma drea } A \text {, emitindo atra } \\
\text { vés dela uma rađiaçlo total de potência } P \text { (energia irradiada por unidade de tempo, po } \\
\text { toda a superficie). Denomina-se radiáncia ou poder emissivo, } R \text {, do objeto, a relaçào: }\end{array}$ & \\
\hline $\begin{array}{l}\text { A unidade de medida dessa grandeza no } \$ \text { í } 1 \text { Wim². Vemos que o valor de R, no SI, } \\
\text { representa a quantidade de energia, em joules, emitida por segundo, em cada metro qua- } \\
\text { drado da superficie do objeto. } \\
\text { Na segunda metade do século XiX, os cientistas austriacos). Stefan e L. Boitzmann } \\
\text { chegaram (o primeiro experimentalmente, e o segundo em teoria) a um resultado, refe- } \\
\text { rente aos corpos negros, denominado lei de Stefan-Boitzmann. } \\
\text { Oenunciado da lei de Stefan-Boltzmann é o seguinte: }\end{array}$ & 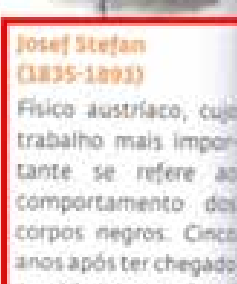 \\
\hline 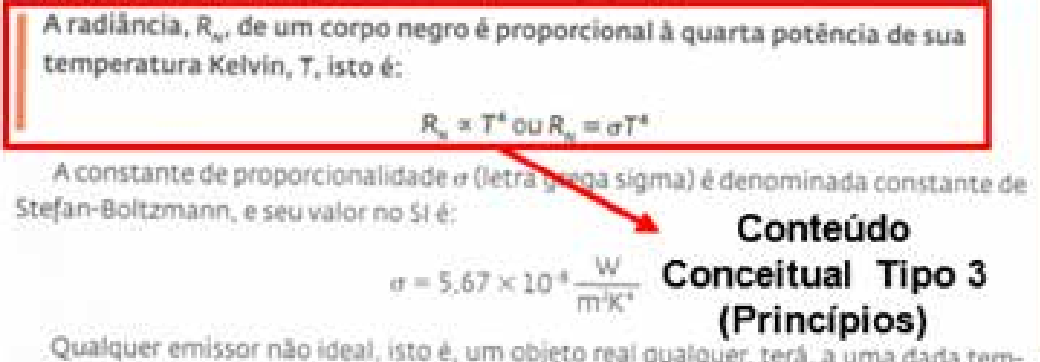 & 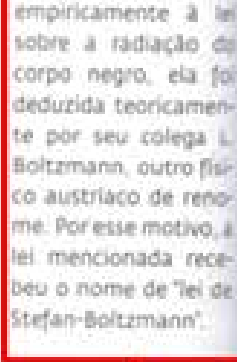 \\
\hline $\begin{array}{l}\text { peratura, uma radiancia } R \text {, menor do que a do corpo negro, ou seja, } R<R \text {, Define-se } \\
\text { emissividade, } e \text {, de um objeto qualquer, da seguinte maneira: }\end{array}$ & \\
\hline 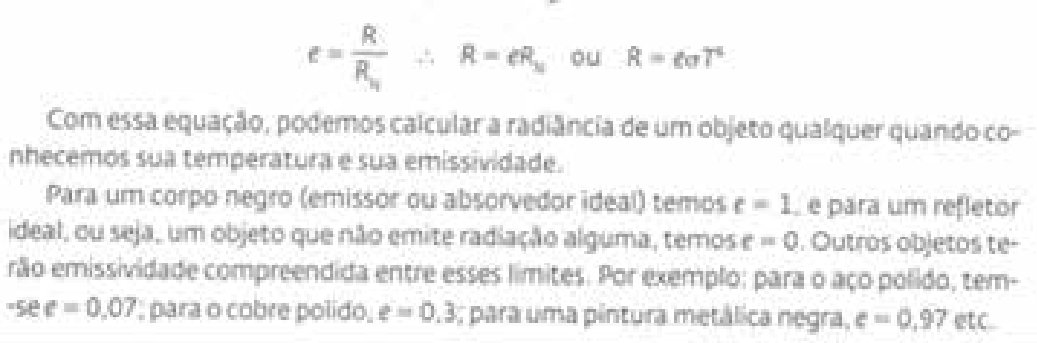 & $\begin{array}{c}\text { Conteúdo } \\
\text { Conceitual } \\
\text { Tipo } 1 \\
\text { (Fatos) }\end{array}$ \\
\hline
\end{tabular}

Fonte: LUZ; ÁLVARES, 2013, v. 2, p. 110.

Observa-se ao longo do texto boxes para leitura, classificados como $\mathrm{CP}$, o que também ocorreu com várias leituras complementares, como nas seções Física no contexto, Integrando... e Infográfico. Também foram classificadas como CP a seção Verifique o que aprendeu e os Exemplos. Em todas as ocorrências de conteúdo procedimental na coleção FCA verificou-se a sua associação a um dos outros dois conteúdos, como mostra a Figura 2. Nesta coleção não foram identificados os Tipos 8 (Elaboração de pesquisa bibliográfica), 10 (Elaboração de questões para enquete) e 13 (Elaboração de perguntas e problemas), tendo maior destaque o conteúdo procedimental do Tipo 6 (Estabelecimento de relações entre fatos, fenômenos e ideias). 
Figura 2 - Exemplo de CA Tipo 3 (Atitudes); CP Tipo 1 (Observação), Tipo 2 (Experimentação), Tipo 9 (Busca de informações),

Tipo 11 (Organização de Informações) e Tipo 12 (Confronto entre suposições)

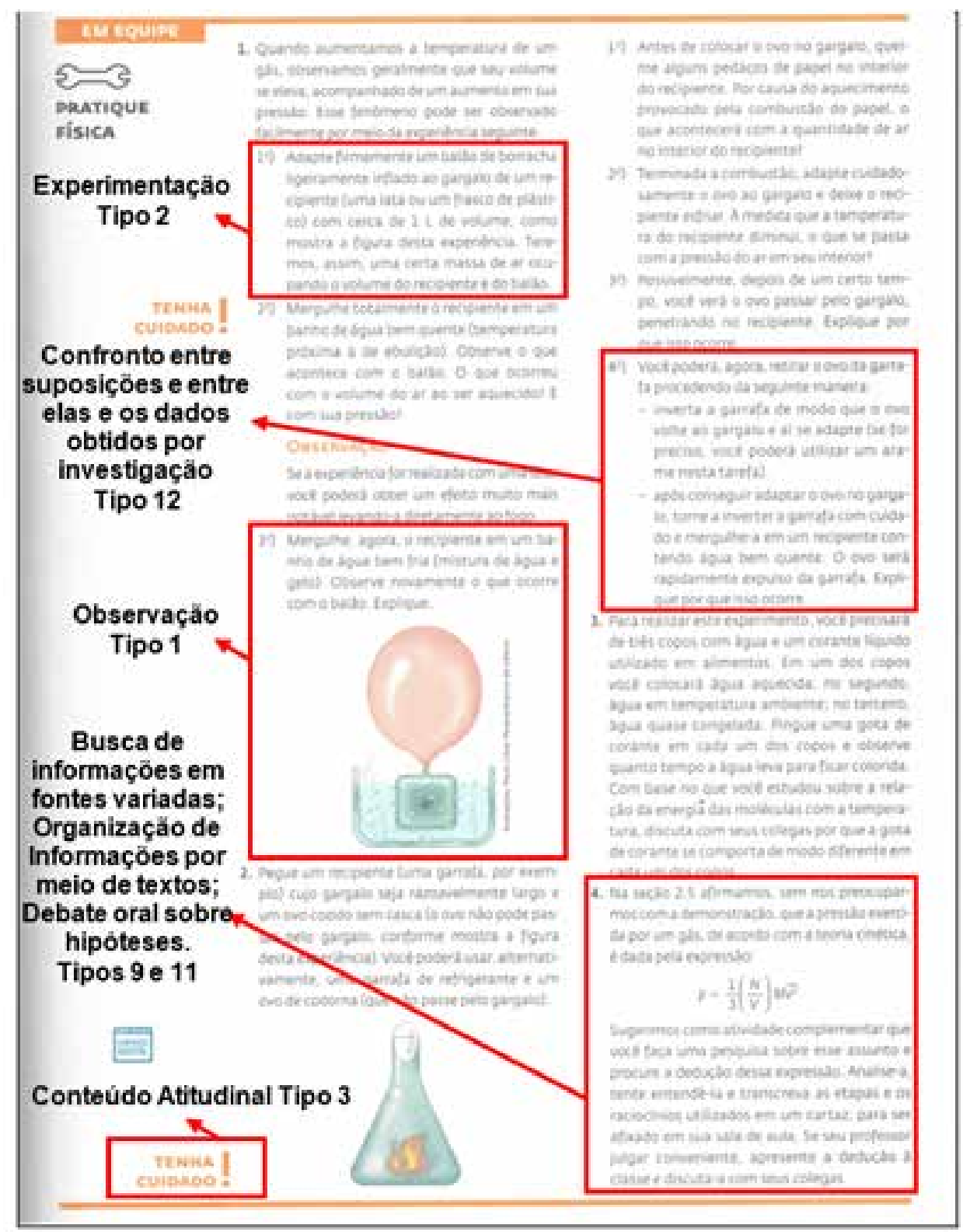

Fonte: LUZ; ÁLVARES, 2013, v. 2, p. 59.

Os conteúdos atitudinais são pouco abordados na coleção FCA e foram localizados juntamente com conteúdo conceitual, recebendo a classificação CA. Em alguns casos aparecem associados aos conteúdos conceitual e procedimental, configurando-se como CPA. Não foi identificado o conteúdo atitudinal Tipo 1 (valores), sendo o Tipo 3 (atitudes) mais frequentes do que o Tipo 2 (normas), este exemplificado na Figura 3: 
Figura 3 - Exemplo de Conteúdo Atitudinal Tipo 2 (Normas) da seção Problemas e testes

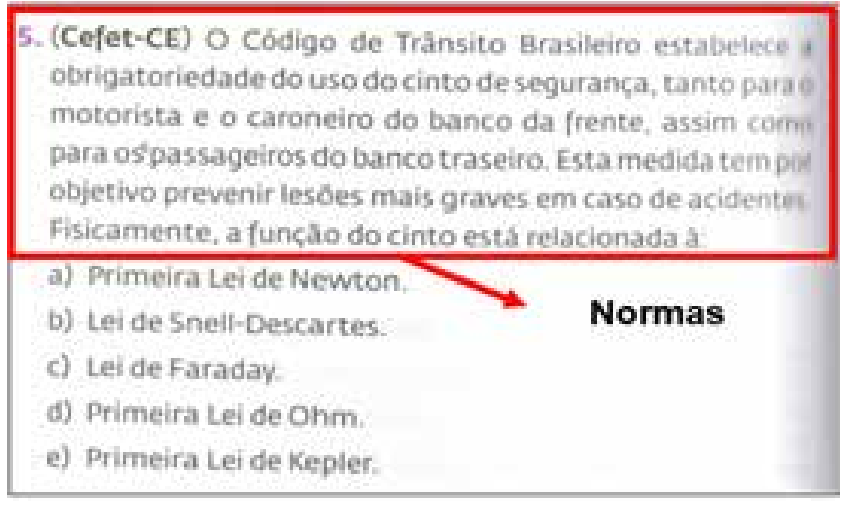

Fonte: LUZ; ÁLVARES, 2013, v. 1, p. 128.

A coleção FCA não menciona as DCNEB e está, segundo os próprios autores, embasada em documentos referenciais, tais como os Parâmetros Curriculares Nacionais, PCN (BRASIL, 1998) e, em suas posteriores orientações, PCN+ (BRASIL, 2002).

\section{CONSIDERAÇÕES FINAIS}

O LD, atualmente acessível a todos os alunos de escolas públicas, por meio do PNLD, é importante fonte de suporte, metodologias e orientações para os professores, configurando-se, portanto, como um forte influenciador da ação docente. Nesse contexto, destaca-se o papel do professor na escolha do LD, em que prepondera tanto a sua experiência profissional quanto a sua formação acadêmica.

Conforme constatado por Calais (2014) e Calais e Martins (2018), a partir da análise das coleções por meio da tipificação de conteúdos proposta por Coll (1987) e Zabala (1998), o termo conteúdos ganha significado mais amplo, ultrapassando o aprender no sentido cognitivo. Assim, verifica-se o conteúdo conceitual presente em todas as páginas das obras consideradas, destacando-se o previsto pelos autores sobre a ênfase desse tipo de conteúdo à medida que se avança no nível de escolarização. Nota-se ainda que o conteúdo atitudinal recebe pouco destaque nos LDs do componente curricular Física, com sua presença mais marcante encontrando-se na coleção SP, se comparada com as demais. Quando se considera essa classificação a partir dos grupos encontrados na análise - conceitual (C), conceitual procedimental (CP), conceitual atitudinal (CA) e conceitual procedimental atitudinal (CPA) - ocorre a predominância do conteúdo tipo $\mathrm{CP}$, em razão do número de atividades e de exercícios resolvidos e propostos. A abordagem dos três tipos de conteúdo no Ensino Médio, em busca de uma formação humana integral, fica então condicionada à forma que o docente optar em utilizar o LD e de sua disponibilidade em propor atividades que vão além do sugerido nesse tipo de material. Nesse sentido, uma boa formação do profissional licenciado em Física, tanto inicial quanto continuada, pode propiciar condições adequadas para extrapolar as proposições do LD.

A categorização sugerida por Prado e Martins (2014) para conteúdos procedimentais mostrou-se de suma importância. Entre os 14 tipos propostos pelas autoras, o tipo de conteúdo procedimental mais abundante em todas as coleções foi o de número 6 
(Estabelecimento de relações entre fatos, fenômenos e ideias), identificado predominantemente nas seções de atividades. Essa característica revela a grande importância dada à resolução de exercícios, em todas as coleções analisadas, que, em alguns casos, consiste em repetições dos exemplos/exercícios resolvidos apresentados ao longo das seções. Em seguida, destacou-se o tipo de conteúdo de número 7 (Leitura e escrita de textos informativos). Os temas apresentados em seções e boxes de leitura apresentam potencialidade para abordagem de outros conteúdos procedimentais, bem como conteúdos atitudinais, principalmente aqueles que se relacionam com os quatro princípios educativos em que está ancorado o conceito de formação humana integral presente nas DCNEB. Em alguns casos aparecem apenas como sugestões de leitura, cabendo ao professor optar ou não por sua utilização. Mais uma vez revela-se a importância do professor na intermediação entre o estudante e o livro didático, uma vez que o docente, a partir de temas relacionados a trabalho, ciência, tecnologia e cultura, poderia intermediar debates e propor atividades diferenciadas que permitissem ao aluno o desenvolvimento de sua formação ética, autonomia intelectual e pensamento crítico.

Conforme revelaram os dados, em uma mesma atividade foram identificados vários tipos de conteúdo procedimental. O Tipo 13 (Elaboração de perguntas e problemas) foi encontrado apenas nas coleções SP e QF, enquanto os tipos 8 (Elaboração de roteiros de pesquisa bibliográfica) e10 (Elaboração de questões para enquete) não foram identificados em nenhuma obra. Além de as coleções não apresentarem todos os conteúdos procedimentais, a sua distribuição ao longo dos livros não é uniforme, ou seja, alguns tipos são mais frequentes do que outros. Os conteúdos que envolvem atividades diferenciadas comumente aparecem em seções complementares, separados dos exercícios e vinculados ao texto principal, cabendo ao professor incluir ou não tais atividades a serem realizadas pelos alunos.

O LD, forte influenciador da ação docente, em muitas ocasiões se configura como principal material didático utilizado em sala de aula. A pesquisa mostrou que são diversos os usos do LD pelos docentes como forma de complementação do conteúdo e fonte de consulta para resenhas e resumos. Sobressai-se, contudo, o seu emprego como principal fonte de exercícios para os alunos, com pouca utilização para realização de atividades diferenciadas. Tal fato pode estar relacionado à preparação inadequada dos docentes, citada por Selles e Ferreira (2004) na dimensão da formação de professores, quando o LD pode chegar a assumir o papel de possível substituto de uma preparação profissional inicial e continuada mais sólida. Dos docentes pesquisados, apenas 45,4\% possuem Licenciatura em Física, enquanto os demais são licenciados em outras áreas do conhecimento. Nesse contexto, destaca-se o papel do professor na escolha e utilização do LD, uma vez que tanto a experiência profissional quanto a formação acadêmica são fatores preponderantes no momento da opção por uma coleção e nas formas de uso em sala de aula. Tal utilização insere-se na dimensão da ação didática, proposta por Selles e Ferreira (2004), na qual o docente se reconhece no LD, que além de oferecer uma seleção de conteúdos a serem ensinados, fornece um conjunto de propostas pedagógicas que passa a influenciar de modo decisivo a ação docente. 
Ao examinar as coleções em busca de informações que revelassem o seu embasamento pedagógico e as situassem dentro do contexto das DCNEB, no que diz respeito ao Ensino Médio, verificou-se que as coleções SP e QF apresentam propostas mais próximas ao conceito de formação humana integral, enquanto a coleção FCA propõe uma formação geral, sem enumerar seus possíveis desdobramentos. As outras coleções limitam-se a tratar da interdisciplinaridade e contextualização, abordagens obrigatórias de acordo com os editais de Convocação do PNLD.

Entende-se que a exemplificação dos diversos tipos de conteúdo e suas categorias pode fornecer subsídios aos professores de Física no planejamento de seu trabalho em sala de aula, buscando promover uma formação humana integral ao aluno, de acordo com o que preconizado nas DCNEB. Assim como partimos dos trabalhos anteriores de Prado e Martins (2014), Calais (2016) e Calais e Martins (2018), deseja-se que esta pesquisa seja fonte de contribuição para investigações futuras, envolvendo a tipologia de conteúdos.

\section{REFERÊNCIAS}

\section{Coleções analisadas}

BONJORNO, José Roberto et al. Física. 2. ed. São Paulo: FTD, 2013. 3 v.

GASPAR, Alberto. Compreendendo a física. 2. ed. São Paulo: Ática, 2013. 3 v.

LUZ, Antônio Máximo Ribeiro da; ÁlVARES, Beatriz Alvarenga. Física contexto \& aplicações. São Paulo: Scipione, 2013. 3 v.

MENEZES, Luís Carlos de et al. Quanta física. 2. ed. São Paulo: Pearson, 2013. 3 v.

STEFANOVITS, Ângelo. Ser protagonista: física. 2. ed. São Paulo: SM, 2013. 3 v.

\section{Demais obras}

BARDIN, Laurence. Análise de conteúdo. Lisboa: Edições 70, 1977.

BOGDAN, Robert C.; BIKLEN, Sari Knopp. Investigação qualitativa em educação: uma introdução à teoria e aos métodos. Porto: Porto Editora, 1994.

BRASIL. Diretrizes Curriculares Nacionais Gerais da Educação Básica. Brasília: Ministério da Educação. Secretaria de Educação Básica, 2013. 562p.

BRASIL. FNDE. Guia de livros didáticos: PNLD 2015: Física: Ensino Médio. Brasília: Ministério da Educação; Secretaria de Educação Básica, 2014. 108p.

BRASIL. Guia Digital do PNLD 2018: Física. Brasília: Ministério da Educação, Secretaria de Educação Básica, 2017. Disponível em: http://www.fnde.gov.br/pnld-2018/. Acesso em: 1o mar. 2019.

BRASIL. Parâmetros Curriculares Nacionais. PCN. Ensino Médio. Brasília: Ministério da Educação; Secretaria de Educação Média e Tecnológica, 1998.

BRASIL. Orientações Complementares aos Parâmetros Curriculares Nacionais. Ensino Médio. PCN+. Brasília: Ministério da Educação; Secretaria de Educação Média e Tecnológica, 2002.

CALAIS, Carlos Wagner Vieira de. A tipologia dos conteúdos de Física nos livros didáticos de ciências do PNLD 2014. 2016. 246f. Dissertação (Mestrado) - Pontifícia Universidade Católica de Minas Gerais, Programa de Pós-Graduação em Ensino de Ciências e Matemática, Belo Horizonte, 2016.

CALAIS, Carlos Wagner Vieira de; MARTINS, Maria Inês. Orientações suplementares aos Guia de Livros Didáticos: tipologia dos conteúdos de Física. In: ENCONTRO DOS MESTRADOS PROFISSIONAIS EM EDUCAÇÃO E ENSINO DE MINAS GERAIS, 2., Belo Horizonte. Atas [...]. Belo Horizonte: PUC MG, 2018.

CHOPPIN, Alain. História dos livros e das edições didáticas: sobre o estado da arte. Educação e Pesquisa, São Paulo, v. 30, n. 3, p. 549-566, set./dez. 2004.

COLL, César. Os conteúdos na educação escolar. In: COLL, César (org.). Os conteúdos na reforma: ensino e aprendizagem de conceitos, procedimentos e atitudes. Porto Alegre: Artmed, 1998. Introdução, p. 9-16. 
COLL, César. Um modelo de currículo para o ensino obrigatório. In: COLL, César. Psicologia e currículo: uma aproximação psicopedagógica à elaboração do currículo escolar. 4. ed. São Paulo: Ática, 1987. p. 153-190.

FERREIRA, Márcia Serra; SELLES, Sandra Escovedo. Análise de livros didáticos em Ciências: entre as ciências de referência e as finalidades sociais da escolarização. Educação em Foco, Juiz de Fora, v. 8, n. 1 e n. 2, p. 63-78, mar./ago. 2003; set./fev. 2004.

MARTINS, Alisson Antonio; GARCIA, Nilson Marcos Dias. Escolha de livros didáticos por professores de Física: artefatos da cultura escolar ou mercadoria? In: ENCONTRO DE PESQUISA EM ENSINO DE FÍSICA, 15., 2014, Maresias. Anais [...]. Rio de Janeiro: SBF, 2014. p. 1-8.

PAVÃO, Antônio Carlos. Ensinar ciências fazendo ciência. Livro Didático em Questão. Boletim 5, p. 7-13, 2006.

PRADO, Betty Carvalho Rocha Gonçalves do; MARTINS, Maria Inês. A tipologia dos conteúdos de Física nos livros didáticos de Ciências Naturais do Ensino Fundamental. In: ENCONTRO DE PESQUISA EM ENSINO DE FíSICA, 15., 2014, Maresias. Anais [...] Rio de Janeiro: SBF, 2014. p. 1-8.

SELLES, Sandra Escovedo; FERREIRA, Márcia Serra. Influências histórico-culturais nas representações sobre as estações do ano em livros didáticos de Ciências. Ciência \& Educação, Bauru, 2004, v. 10, n. 1.

SILVA, Shirley Maciel da. Biblioteca Professor Manoel Lopes de Siqueira: trajetórias. Belo Horizonte: Clio Gestão Cultural e Editora, 2017. 243p.

ZABALA, Antoni. A prática educativa: como ensinar. Porto Alegre: Artmed, 1998.

ZAMBON; Luciana Bagolin; TERRAZAN, Eduardo A. Critérios para a escolha de livros didáticos utilizados por professores de Física. In: ENCONTRO DE PESQUISA EM ENSINO DE FÍSICA, 14., 2012, Maresias. Anais [...] Rio de Janeiro: SBF, 2012. p. 1-9. 